\title{
Miren Lacassagne et Thierry Lassabatère (dir.), Eustache Deschamps, témoin et modèle. Littérature et société politique (XIV ${ }^{\mathrm{e}}-\mathrm{XVI}$ siècle)
}

G. Matteo Roccati

\section{OpenEdition}

\section{Journals}

Édition électronique

URL : http://journals.openedition.org/studifrancesi/5527

DOI : 10.4000/studifrancesi.5527

ISSN : 2427-5856

Éditeur

Rosenberg \& Sellier

Édition imprimée

Date de publication : 1 septembre 2011

Pagination : 384-385

ISSN : 0039-2944

\section{Référence électronique}

G. Matteo Roccati, « Miren Lacassagne et Thierry Lassabatère (dir.), Eustache Deschamps, témoin et modèle. Littérature et société politique (xIV-xvi ${ }^{\mathrm{e}}$ siècle) », Studi Francesi [En ligne], 164 (LV | II) | 2011, mis en ligne le 30 novembre 2015, consulté le 09 janvier 2021. URL : http://journals.openedition.org/ studifrancesi/5527; DOI : https://doi.org/10.4000/studifrancesi.5527

Ce document a été généré automatiquement le 9 janvier 2021

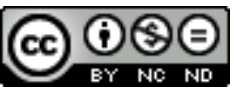

Studi Francesi è distribuita con Licenza Creative Commons Attribuzione - Non commerciale - Non opere derivate 4.0 Internazionale. 


\title{
Miren Lacassagne et Thierry Lassabatère (dir.), Eustache Deschamps, témoin et modèle. Littérature et société politique $\left(\mathrm{XIV}^{\mathrm{e}}-\mathrm{XVI} \mathrm{I}^{\mathrm{e}}\right.$ siècle)
}

\author{
G. Matteo Roccati
}

\section{RÉFÉRENCE}

MIREN LACASSAGNE et THIERRY LASSABATÈRE (dir.), Eustache Deschamps, témoin et modèle. Littérature et société politique (XIV -XVI siècle), Paris, PUPS (Presses de l'Université ParisSorbonne), 2008 («Culture et civilisation médiévales»), 280 pp.

1 Les articles de ce recueil reprennent les communications présentées lors du II ${ }^{\mathrm{e}}$ colloque international de Vertus. La préface de Philippe contAmine est suivie de l'article liminaire de Jean-Claude MÜHLETHALER, Entre amour et politique: la fable d'Hermaphrodite à la fin du Moyen Âge. Pour une relecture du "Lay amoureux" d'Eustache Deschamps, pp. 11-29, sur la fortune et la signification de la figure ovidienne d'Hermaphrodite chez Deschamps et plusieurs autres auteurs. L'ouvrage est ensuite organisé en quatre parties. Dans la première (La poésie au service d'une écriture de l'histoire) María Narbona CÁRCELES, La contribution d'Eustache Deschamps à la construction du mythe de Charles, dit "Le Mauvais", à partir de la "Fiction du Lyon", pp. 33-47, étudie la présentation du personnage à travers l'allégorie: l'œuvre de Deschamps est parmi les textes fondateurs de l'image négative véhiculée par la propagande royale; Clotilde DAUPHANT, Le cycle de l'avènement de Charles VI dans le manuscrit des œuvres complètes d'Eustache Deschamps (pièces 164 à 172), pp. 49-66, considère ce groupe de pièces comme un tout et en donne un commentaire qui en souligne l'homogénéité. 
2 La deuxième partie (Un Discours aux marges du genre poétique) comprend les contributions suivantes: Aurélie MAZINGUE, Les indices de la théâtralité dans la poésie d'Eustache Deschamps, pp.69-88; Karin BECKER, La corporalité du «povre Eustace»: le moi physique revisité, pp.89-102, sur l'évolution de l'attitude de la critique dans l'interprétation de la poésie de Deschamps, dont la «mise en scène» du moi physique est un des traits caractéristiques; Laura KENDRICK, Le Miroir de mariage: mode d'emploi, pp.103-116; Madeleine JEAY, Pour dépasser la polémique, la leçon d’une fable «écologique» (ballade 1103), pp. 117-130.

3 La troisième partie (Eustache Deschamps à la cour de Charles VI) rassemble une présentation de La base Charles VI: une ouverture vers le monde d'Eustache Deschamps, pp.133-145, par les membres de l'opération Charles VI: l'architecture et le fonctionnement de la base prosopographique sont rapidement décrits ainsi que les corpus d'où sont tirées les données; Christine BARRALIs, Eustache Deschamps et les prélats de cour: l'exemple des Dormans, pp.147-157, traite de quelques personnages mentionnés dans les textes de Deschamps et souligne la coexistence d'attitudes contradictoires: moraliste et courtisane; Héléne MILlET, Eustache Deschamps, précoce témoin de la dévotion aux «saints privilégiés», pp. 159-171, identifie dans une hymne latine la source directe d'une des deux ballades que Deschamps consacre à cette dévotion ( ${ }^{\circ} 32$, l'autre étant la 1237) et dresse un relevé des livres d'Heures (qu'elle date et dont elle précise la provenance) où elle apparait.

4 On trouvera dans la quatrième partie (Intertextualité et transmission des manuscrits) les articles de Ludmilla ЕVDокімоva, Le "Miroir historial" de Jean de Vignay et sa place parmi les traductions littérales du XIV siècle, pp. 175-191; Zoltán JENEY, «Si tu veuls vivre en court...». Deschamps et Du Bellay, un intertexte possible, pp.193-202; Miren LACASSAGNE, Rabelais lecteur de Deschamps: le "Miroir de mariage" et le "Tiers Livre", pp. 203-220; Thierry LASSABATÈRE, Racines médiévales de la culture politique nobiliaire à l'époque moderne: la lecture d'Eustache Deschamps aux $\mathrm{XVI}^{e}$ et $\mathrm{XVII}$ siècles, pp. 221-236, qui identifie quelques possesseurs de manuscrits d'œuvres de Deschamps et analyse leur culture; Anne M. DROPICK, Du renouvellement à la transformation: typologie scolaire des textes de conseil d'Eustache Deschamps jusqu'au XvI siècle, pp. 237-247, qui étudie le contexte dans lequel sont copiés les textes de Deschamps (elle en signale pour la première fois deux d'entre eux transmis par le ms. 2602 de Vienne: $\mathrm{n}^{\text {os }} 99$ et 394).

5 Le volume comporte également une Bibliographie générale (pp. 249-266) et les Index des Noms de personnages historiques, mythologiques, bibliques ou de fiction, et auteurs anciens, des Noms de lieux, des Notions et figures allégoriques. 